\section{The Use of Cognitive Mapping Technique in Management Research: Theory and Practice}

by Rusli Ahmad and Noor Azman Ali

\section{Introduction}

The purpose of this article is to analyse the use of a qualitative approach using cognitive mapping techniques in the study of a decision-making process. This study takes place in a public sector and in the context of a performance appraisal system (PAS). This is in line with recommendations by scholars and researchers to conduct a management research in a public service context (see Brown, 1999; Bissessar, 2000; Jabroun and Balakrishnan, 2000; O’Donnell and O’Brien, 2000; Redman, Snape and Thompson, 2000). This article also intends to elucidate and justify the methodological approach used, examine the assumptions underlying the use of a particular research design, and provide arguments for the preference of the methodology used. It is hoped that this will contribute to the understanding of the nature and validity of the research undertaken. This article begins by reviewing the theoretical issues of the research framework, the main features of the qualitative methodologies, and finally, the research method applied in this research is determined and justified.

\section{Research Background}

Research is essentially an attempt to increase a body of knowledge through the discovery of new facts and relationships by a process of systematic enquiry (Nachmias and Nachmias, 1996). The research investigation must be logical, systematic, scientific, and concerned with seeking solutions to problems and answering research questions (Allison, 1994). As a result, one key to good research lies in selecting the most powerful research design and methods. Designing a research study involves a choice of research approach. There are three general categories of research approaches, namely Exploratory, Descriptive, and Causal (Sekaran, 1992). Each category differs from the others in terms of research purposes, research questions, the precision of the formulated hypotheses, and the data collection methods that are used. It is important for the researcher to choose the most appropriate research approach to suit his/her study. It is important, because it will affect the reliability and validity of the research outcomes.

This article concentrates only on exploratory research which aims to gain insights and ideas (Sekaran, 1992). It is particularly helpful in breaking broad, imprecise problem statements into smaller and more precise subproblem statements (Aacker et.al., 1995). This research can be used to establish priorities among research questions, and for learning about practical
Biographical Notes

Rusli Ahmad is Lecturer in the Faculty of Cognitive Sciences and Human Development, Universiti Malaysia

Sarawak, 94300

Sarawak, Malaysia.

Noor Azman Ali is

Lecturer in the Faculty of Economics and

Management, University

Putra Malaysia.

Both authors can also be contacted at Bradford

University School of

Management, Emm Lane, Bradford, West

Yorkshire, England BD9

4JL. 